\title{
Sand Casting of Sheet Lead: Numerical Simulation of Metal Flow and Solidification
}

\author{
Arun Prabhakar, Michail Papanikolaou*, Konstantinos Salonitis and Mark Jolly \\ Manufacturing Theme, Cranfield University, Cranfield MK43 0AL, UK
}

*Corresponding Author: Michail Papanikolaou, m.papanikolaou@cranfield.ac.uk, +44 (0) 1234758235

\begin{abstract}
Sandcast lead sheets are characterised by their superior aesthetic performance and mottled surface. Lead sheet casting is widely used in the construction industry for roofing and flashing applications, while the roots of this process can be tracked back to the Roman times. In this study, two-dimensional Computational Fluid Dynamics (CFD) simulations have been performed to simulate the melt flow and solidification stages of the lead sandcasting process. The effects of process parameters such as pouring temperature, screed velocity and clearance between the screed and the sandbed on the final quality of the lead sheet are investigated. Lead sheet quality has been quantified by measuring the variance and the average value of the final sheet thickness over the sandbed length. The developed CFD model has been validated against experimental results by comparing the time evolution of the lead-sandbed interface temperature against data collected by thermocouples during the real-time process. The numerical results show that all of the aforementioned parameters affect the final quality of the cast product and suggest that superior quality lead sheets can be produced for a range of relatively low values of the pouring temperature and slow strickle motion.
\end{abstract}

Keywords: Sheet casting, CFD, lead, sheet thickness

\section{Introduction}

Casting is one of the oldest manufacturing processes and dates back to $3600 \mathrm{BC}$ [1]. Green sand casting is one of the most commonly used and preferred methods for manufacturing near net shape parts due to the easy availability of raw materials, its low cost and recyclability [2]. Lead has been one of the earliest metals to be used among other metals including gold, silver, copper, iron and tin. Its unique properties such as high malleability, high ductility and resistance to atmospheric oxidation were known since ancient times. Romans used sheet lead for many applications such as roofing, manufacture of water pipes and sarcophagi [3, 4]. Moreover, lead has been proven to be fully recyclable, resistant to corrosion and environmentally friendly [5]. During the last decades, about $85 \%$ of the sheet lead manufactured is used for roofing and flashing applications [6].

Lead sheet used for construction purposes is mostly produced from recycled lead via three main techniques. The majority of lead sheets are produced by rolling, which involves casting lead slabs and then rolling them in a mill until the desired thickness has been obtained [7]. In another direct method, sheet of specific thickness is continuously cast upon a rotating water-cooled drum in a bath of molten lead [8]. Rolled lead sheet are often preferred due to their thickness consistency ( $\mp 5 \%$ tolerance) and their compatibility to the British and European Standard, BSEN 12588 [9]. The most traditional method of manufacture of lead sheets employs the sand casting technique [3]. Sandcast lead sheets are mainly used for roofing purposes in the heritage industry, mostly for renovating old churches, cathedrals, state homes etc., due to their attractive sheen and superior appearance compared to rolled sheet. Although 
sandcast lead sheet is only available in standard codes $6-8(2.65-3.55 \mathrm{~mm})$, it can be manufactured to the provided specifications and contribute to reduced waste and increased savings.

The lead sheet sandcasting process essentially consists of two main stages, namely: (a) pouring molten lead on a sand bed and (b) smearing of the melt surface using a strickle [10]. The process starts with preparing the rectangular sand mould, usually $3-7 \mathrm{~m}$ long and $0.75-1.3 \mathrm{~m}$ wide. The sandbed surface is flattened using a strickle guided by a screed as illustrated in Figure 1 and smoothened using a steel floater to avoid any surface undulations. Molten lead is then poured at around $350{ }^{\circ} \mathrm{C}$ using a hopper from the one end of the bed. After pouring, the strickle which is guided by a screed rail is used to smear the flowing melt along the mould (Figure 2) and seconds later, the melt solidifies into a sheet.

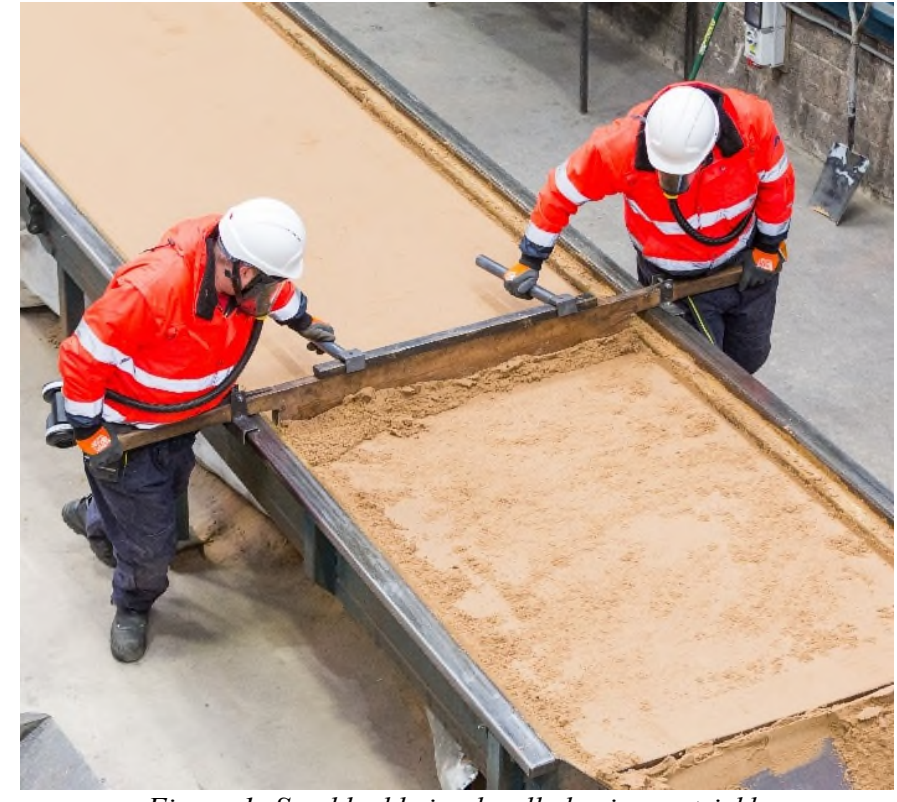

Figure 1: Sand bed being levelled using a strickle

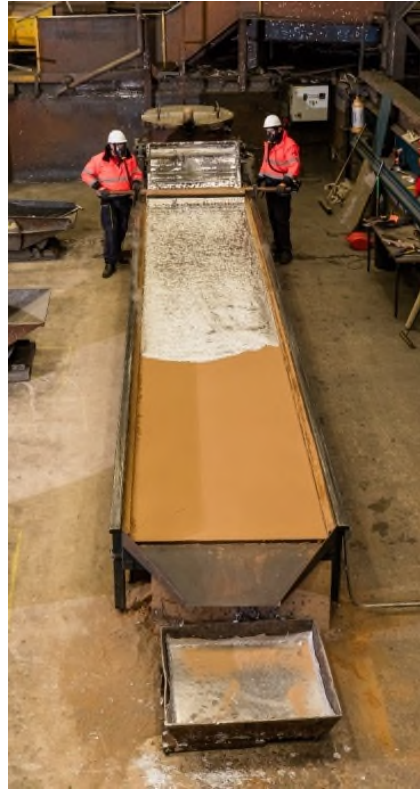

Figure 2: Setup for traditional sand casting of sheet lead

Although both continuous casting and rolling of lead sheet have been investigated using both numerical and experimental studies ([11-16]), the lead sheet sandcasting technique has not been thoroughly investigated yet, with the exception of a recent study [10], focused on characterising the mechanical properties of sand cast lead sheet. It is evident that there is still limited knowledge in this area with respect to the effects of process parameters, such as the pouring temperature and strickle velocity, on the quality of the final cast product. In fact, till nowadays, the control of the process parameters relies solely on the experience and intuition of foundry engineers and operators. However, reliable numerical models can contribute towards the effective selection of the optimum process parameters without the need to conduct a large number of time consuming and energy intensive experiments.

Nowadays, the evolution of the computing power as well as the modelling techniques has made the numerical investigation of casting processes feasible [17]. The sand casting process in particular has been extensively studied by means of CFD simulations. Among various topics, defect prediction in sand casting is one of the well-researched areas. A critical review of the existing modelling techniques for the prediction of defects due to air entrainment and oxide formation as well as their benefits and limitations has been provided by Reilly et al. [18]. The authors suggested that, although significant progress has been made with regard to modelling casting defects, simulation engineers should closely collaborate with experimentalists in the future in order to develop computational models for the realistic representation of the mechanisms of defect nucleation and growth. Reis et al. [19] developed their own core code based on the Finite Volume Method (FVM) to predict the formation of shrinkage defects and validated their numerical results against experiments. Their model was proven to be capable of predicting various types of shrinkage defects such as porosity by surface initiation, external and internal 
porosity. Sulaiman et al. [20] performed a thermal analysis of the molten metal during the filling of a sand mould and compared their results with experimental data. Thermocouples were inserted at different points in the mould and some differences were observed between the experimental and model temperature data. These deviations were attributed to the presence of air in between sand particles that were not accounted in the model. CFD simulations have also been performed for proposing modifications in sand moulds in order to ensure uniform filling and defect-free cast components. In this context, Kermanpur et al. [21] modelled the metal flow and solidification of cast iron in complex multicavity automotive components while their model was validated against experimental observations. More specifically, the authors observed the filling flow patterns obtained from their simulations, identified the areas with increased probability of air entrainment and proposed design modifications which led to more uniform filling. In more recent investigations, optimisation schemes have been coupled with CFD solvers to optimise one or multiple parameters of sand casting processes in order to improve the energy efficiency of the process and eliminate defects in the cast product $[22,23]$. Krimpenis et al. [24] focused on the optimisation of the High Pressure Die Casting (HPDC) process with respect to the solidification/filling times and the defects of the final cast product. However, instead of employing implementing optimisation algorithms, they performed Design of Experiments (DoE) to build a database which was subsequently used for training a feedforward Artificial Neural Network (ANN). The trained ANN was capable of fairly predicting the output variables of their model with a mean relative error less than $10 \%$. Their adopted approach is considered to be time efficient as successfully trained ANNs can eliminate the need for performing a large number of simulation runs.

Despite the extensive application of CFD in metal casting, the lead sheet casting process has not yet been numerically investigated according to the authors' best knowledge. Although lead sheet sand casting falls into the category of sand casting processes, the nature of the process is quite different from traditional sand casting as liquid lead solidifies on top of a sandbed instead of inside a mold cavity and it also involves smearing the liquid lead on the sandbed with a strickle. Moreover, the final cast component (sheet) is very thin compared to traditional sandcast components. As a result, CFD modelling of such a process involves a number of challenges related to the mesh generation, free surface flow and turbulence modelling. This investigation aims to shed light on the effects of three main process parameters (pouring temperature, strickle-sandbed clearance and strickle velocity) on the final quality of sandcast lead using a two-dimensional CFD model. This is the first attempt to investigate the lead sheet casting technique via numerical simulation. A CFD model was developed to simulate the filling and solidification stages of the process. The final quality of the sheets was quantified by measuring their roughness and average thickness. The developed CFD model was validated using temperature data at the fluid-sandbed interface collected from real-time experiments.

\section{Methodology}

\subsection{Model theory}

In this section the main theoretical concepts involved in this investigation will be discussed. The commercial CFD software Flow-3D [25] was used to simulate the filling and solidification stages of the process. Flow-3D employs either finite difference or finite volume approaches to numerically solve the equations of fluid motion and heat transfer. Flow-3D is based on the Fractional-Area-VolumeObstacle-Representation (FAVOR) method to describe the fluid motion and heat transfer in the vicinity of fluid/obstacle interfaces and the Volume-of-Fluid (VOF) method to track sharp interfaces [26]. The FAVOR equations for an incompressible and viscous fluid are summarised as follows:

$$
\nabla \cdot(\boldsymbol{A u})=0
$$




$$
\begin{gathered}
\frac{\partial \mathbf{u}}{\partial \mathrm{t}}+\frac{1}{V}(\boldsymbol{A} \boldsymbol{u} \cdot \nabla) \boldsymbol{u}=-\frac{1}{\rho} \nabla \mathbf{p}+\frac{1}{\rho V}(\nabla \boldsymbol{A}) \cdot(\mu \nabla) \boldsymbol{u}+g \\
\frac{\partial H}{\partial \mathrm{t}}+\frac{1}{V}(\boldsymbol{A} \boldsymbol{u} \cdot \nabla) H=\frac{1}{\rho V}(\nabla \boldsymbol{A}) \cdot(k \nabla T)
\end{gathered}
$$

where:

$$
\boldsymbol{A} \boldsymbol{u}=\left(A_{x} u_{x}, A_{y} u_{y}, A_{z} u_{z}\right) \quad \nabla \boldsymbol{A}=\left(\frac{\partial}{\partial x} A_{x}, \frac{\partial}{\partial y} A_{y}, \frac{\partial}{\partial z} A_{z}\right)
$$

and

$$
H=\int C(T) d T+\left(1-f_{S}\right) \cdot L
$$

In equations (1)-(3), $A_{i}$ is the fraction of the open area in the $i^{\text {th }}$ direction, $u_{i}$ the velocity component in the $i^{\text {th }}$ direction, $T$ the fluid temperature, $\mu$ the fluid viscosity, $V$ the open volume fraction, $H$ the fluid enthalpy, $\rho$ the fluid density and $p_{i}$ the pressure component in the $i^{\text {th }}$ direction. The symbols $L, C$ and $f_{s}$ refer to the latent heat, specific heat and solid fraction respectively. The temperature of the mould is given by:

$$
\frac{\partial T_{m}}{\partial t}=\frac{1}{\rho C_{m} V_{c}}\left(\boldsymbol{A}_{c}\right) \cdot\left(k_{m} \nabla T_{m}\right)
$$

where the subscripts $m$ and $c$ refer to the mold and complementary quantities respectively. The heat flux at the metal mold interface is calculated according to:

$$
q=h\left(T-T_{m}\right)
$$

where $h$ is the heat transfer coefficient at the interface.

The Volume-of-Fluid (VOF) method employed in this study is widely used for tracking free surfaces at the interface between liquid metal and surrounding air. According to this algorithm the free surface can be tracked based on 3 main principles:

1. The fluid fraction is a function of the position and the time $(F=F(t, \boldsymbol{r}))$. Its value is equal to 1 at the fluid region, 0 at the void region while $0<F<1$ at the free surface region.

2. The donor-acceptor advection method is employed for the reconstruction of the free surface [27]. According to this method the free surface is constructed based on the values of $F$ (Equation (6)) in the computational cell and the surrounding ones.

$$
\frac{\partial F}{\partial t}+\frac{1}{V} \nabla \cdot(\boldsymbol{A u} F)=0
$$

3. The boundary conditions at the free surface are zero normal and tangential stresses.

\subsection{Simulation Setup}

As stated in the introduction, the lead sheet casting process consists of two main sub-processes: (a) pouring the molten metal onto a sand bed and (b) smearing of the melt surface using a strickle. As illustrated in the flow chart of Figure 3, the process starts with melting a mixture of scrap lead and refined lead in a furnace at $450{ }^{\circ} \mathrm{C}$. Molten metal is then poured into a hopper where the dross is removed. Meanwhile, the casting bench is filled with a green sand mixture which is subsequently levelled and smoothened to attain a flat surface. The temperature of the metal is being constantly 
measured using a thermocouple and pouring starts when the lead temperature has reached $345{ }^{\circ} \mathrm{C}$. Temperatures lower than this value might lead to premature solidification (liquid lead might not reach the end of the bed), while higher temperature might lead to sheets with increased surface irregularities and thickness lower than the desired value, as it will be shown in the results section. In this investigation the focus is laid explicitly on the pouring and solidification stages of the process.

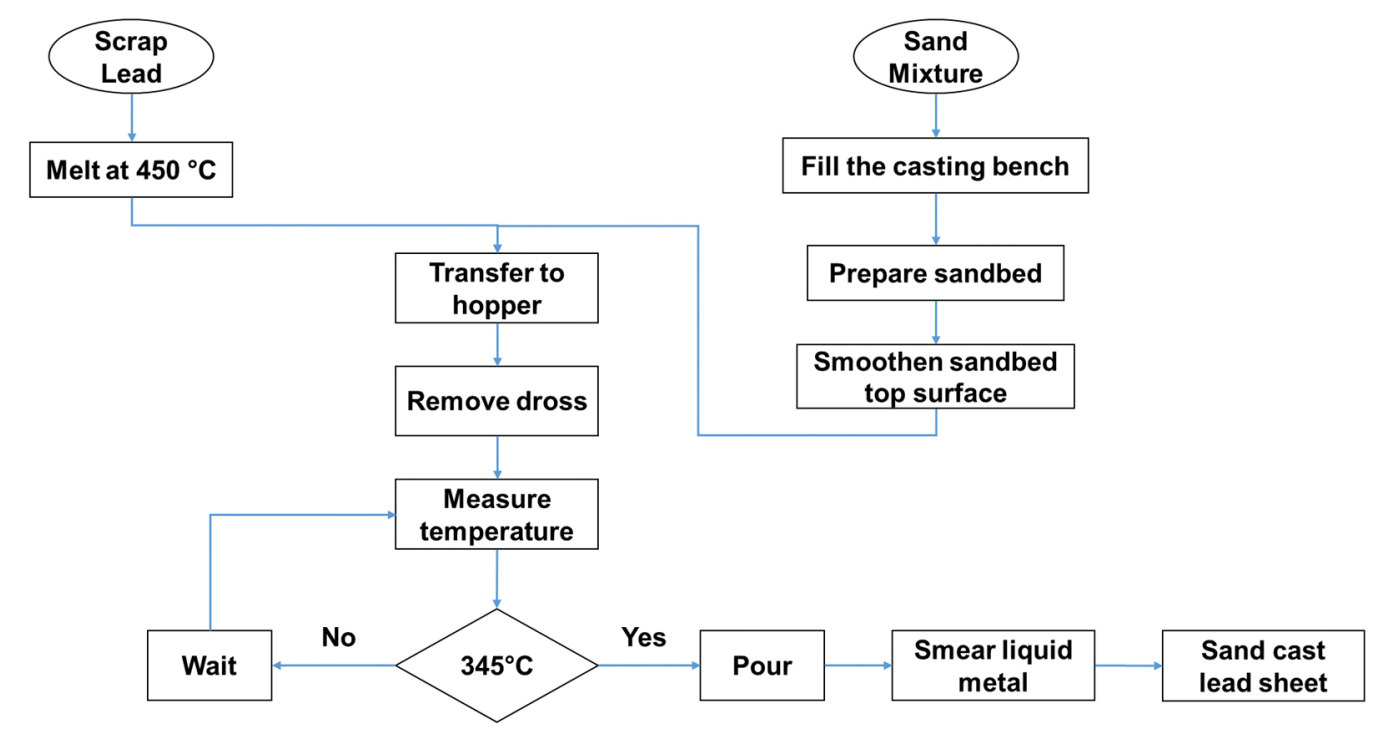

Figure 3: Process flow chart of the lead sheet casting process

As illustrated in Figure 4(a), a typical sand-casting setup for sheet lead manufacture consists of 3 components: (a) a sandbed, (b) a wooden strickle and (c) an inclined plane made of steel. The dimensions of each component are depicted in Figure 4(b). For the simulation setup a $3 \mathrm{~m}$ long sandbed was considered. This value was selected because it is large enough to provide an accurate estimate of the lead sheet quality while maintaining the computational cost within acceptable limits. Moreover, as it will be presented in the following sections both the flow and temperature fields are stabilised after the first $50 \mathrm{~cm}$ of the horizontal section of the sandbed $(x \geq 1 \mathrm{~m})$. The CFD model was limited to two directions in favour of computational efficiency since the flow and temperature fields are not expected to change in the transverse direction (y-direction). Moreover, the effects of the sandbed walls with respect to heat transfer and shear stress are not dominant across the transverse direction considering that the contact area of liquid lead with the walls is very small compared to the corresponding one with the sandbed.

\begin{tabular}{|c|c|}
\hline Component & Material \\
\hline Sand bed & Silica Sand \\
\hline Inclined plane & Stainless steel \\
\hline Strickle & Wood \\
\hline
\end{tabular}

\begin{tabular}{|c|c|}
\hline Density* $\left[\mathrm{kg} / \mathrm{m}^{3}\right]$ & 10,600 \\
\hline Viscosity* [Pa·s] & 0.0027 \\
\hline Specific Heat* $[J /(\mathrm{kg} \cdot \mathrm{K})]$ & 143 \\
\hline Thermal conductivity $[\mathrm{W} /(\mathrm{m} \cdot \mathrm{K})]$ & 33 \\
\hline Heat transfer coefficient (lead $/$ void) $\left[\mathbf{W} /\left(\mathbf{m}^{2} \cdot \mathbf{K}\right)\right]$ & 30 \\
\hline $\begin{array}{l}\text { Heat transfer coefficient (lead/sandbed) } \\
{\left[\mathrm{W} /\left(\mathbf{m}^{2} \cdot \mathbf{K}\right)\right]}\end{array}$ & 1000 \\
\hline Heat transfer coefficient (lead/strickle) $\left[\mathrm{W} /\left(\mathbf{m}^{2} \cdot \mathbf{K}\right)\right]$ & 1000 \\
\hline $\begin{array}{l}\text { Heat transfer coefficient (lead/inclined plane) } \\
{\left[\mathrm{W} /\left(\mathbf{m}^{2} \cdot \mathbf{K}\right)\right]}\end{array}$ & 8000 \\
\hline Melting Point $\left[{ }^{\circ} \mathrm{C}\right]$ & 327 \\
\hline
\end{tabular}

Table 2: Lead $(\mathrm{Pb})$ properties [28]

The material properties corresponding to each component were taken from the Matweb online materials database [28] while the heat transfer coefficients at the interfaces of the molten metal and each component were set according to [29]. Based on the measurements taken during the experiments conducted, the initial temperature for each component was set equal to $15{ }^{\circ} \mathrm{C}$, as well as the room 
temperature. Metal pouring was simulated using a rectangular metal source placed on top of the inclined plane while the velocity normal to the metal source area was selected to be constant during the first 2.5 seconds of the simulation and equal to $1.14 \mathrm{~m} / \mathrm{s}$. The value of the velocity was calculated according to equation (7) and selected so as to satisfy a mass flow rate $(\dot{m})$ equal to $392 \mathrm{~kg} / \mathrm{sec}$ as suggested by the experimental setup.

$$
u=\frac{\dot{m}}{\rho A}
$$

Subsequently, the source was removed and the strickle was displaced vertically up to the point of the desired clearance between the strickle and the sand bed. Then the strickle was assigned a constant velocity ranging from 1-1.6 m/s, depending on the case under examination, parallel to the sand bed (xdirection). The lead properties used for the simulation setup are listed in Table 2. The values of the properties denoted with a star $(*)$ refer to the melting point of lead and have been considered to be dependent on the lead temperature during the simulation [30].

(a)

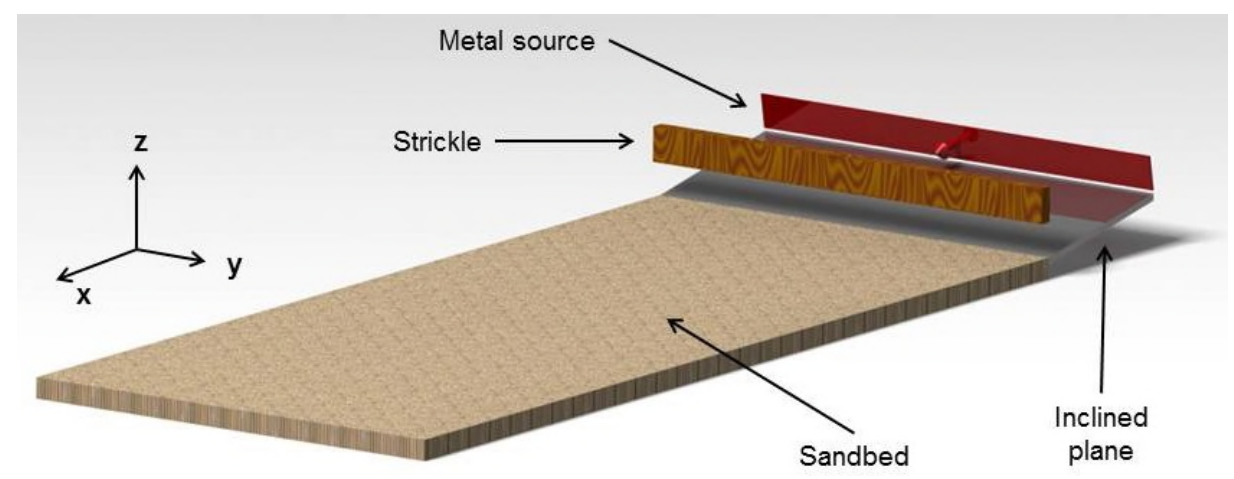

(b)

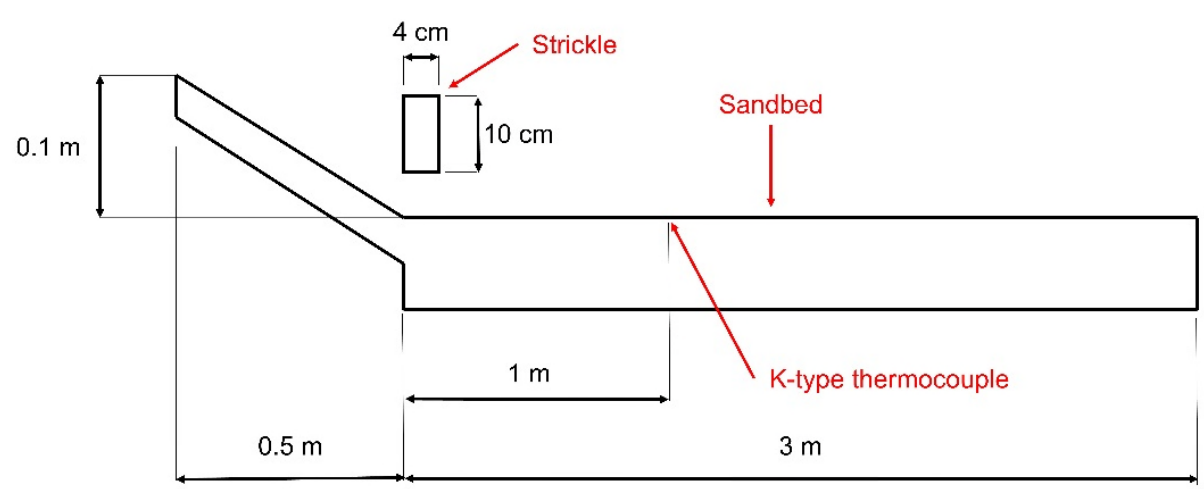

Figure 4: (a) Schematic illustration and (b) sketch of the simulation setup

A rectangular mesh was utilised in order to solve the mass, momentum, energy and heat transfer equations. Due to the enhanced resolution required at the interface between the sandbed and the liquid lead (boundary layer), an increasingly finer mesh was introduced at the vicinity of the aforementioned area as illustrated in Figure 5. In order to achieve high accuracy, the cell size across the direction normal to the sandbed was set equal to $0.5 \mathrm{~mm}$ in order to have at least 4 fluid cells along the minimum cross section of the setup; this corresponds to the clearance between the sandbed and the strickle, which ranges between 2.5 and $4 \mathrm{~mm}$. In order to maintain an aspect ratio equal to 3 across the simulation domain, the maximum dimension of the cells was consequently set equal to $1.5 \mathrm{~mm}$. The final constructed mesh consisted of 237,168 cells in total. The mesh was confined to the solid components of the simulation domain (inclined plane, sandbed and strickle) with an overlap length equal to $5 \mathrm{~cm}$. Symmetry boundary conditions were applied across all the mesh boundaries, except of $z_{\max }$ where a 
pressure boundary condition was applied and $\mathrm{x}_{\max }$ which was defined as an outflow boundary. Finally, a no slip condition was applied at the mold/lead and strickle/lead interfaces.

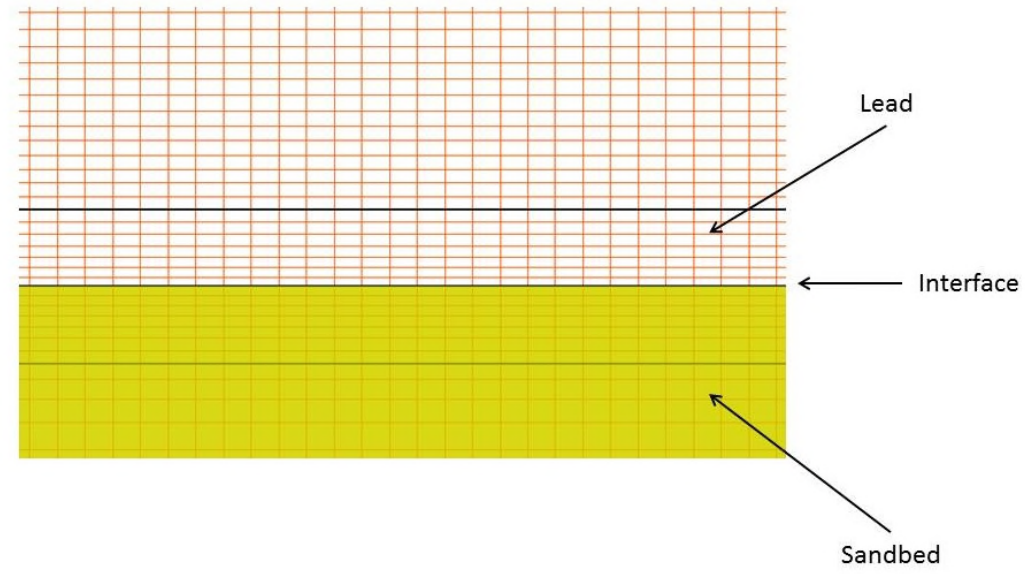

Figure 5: Mesh resolution

The developed model accounted for surface tension which was considered to be equal to $\gamma=0.439 \mathrm{~kg} / \mathrm{s}^{2}$ while a full flow shrinkage model was used in favour of computational accuracy [31]. Moreover, the Renormalized Group (RNG) model was employed for modelling turbulence [32]. For each simulation performed the fluid momentum and continuity equations were solved, while a first-order method was used for the approximation of the momentum advection.

\subsection{Model verification}

Experiments were conducted on a $7 \mathrm{~m}$ long sand bed at Midland Lead, a foundry based in Derby UK, with a $99.9 \%$ pure recycled lead charge. When conducting experiments, it was essential that the liquid melt was smeared using the strickle before it completely solidified to attain a flat top surface; any delays would result in premature solidification and consequently sheets with higher thickness than the desired value. On the other hand, the strickle motion should not commence very early as this would result in additional melt solidifying on top of the flat surface already created by the strickle motion. During the process, shims were used in between the strickle and the screed rail to adjust the clearance between the sand bed and the bottom surface of the strickle.

The verification of the CFD model was based on the comparison of the cooling curves of liquid lead obtained from experimental and numerical results respectively. This strategy has been also been used in past investigations for validating numerical models against experimental ones [33, 34]. Similar cooling curves between the experimental and numerical results would be indicative of the appropriate selection of heat transfer coefficients, material properties and solidification models employed. To obtain the experimental temperature measurements, one K-type thermocouple was inserted from beneath the sand bed and placed at the sandbed/lead interface at a distance equal to $1 \mathrm{~m}$ from the end of the inclined plane (Figure 4(b)). An 8-channel thermocouple data acquisition module (Pico TC-08) coupled with the software PicoLog 6 was used to collect temperature data at equally spaced time intervals of 1 second. In order to meaningfully compare the experimental results with the numerical ones, the simulation parameters (pouring temperature, clearance, strickle motion onset time and speed) were set so as to accurately replicate the experimental conditions.

In Figure 6, the collected temperature data are plotted as a function of time along with the temperature of a probe of the simulation domain with the identical position, located at the interface between the sandbed and the lead. Moreover, it has to be noted that $\mathrm{t}=0$ corresponds to the time when the strickle starts moving while both the experimental and simulation results correspond to a lead sheet with 
thickness equal to $4 \mathrm{~mm}$. It is evident the numerical results are in very good agreement with the experimental ones; thus, the model is considered to be adequate and accurate enough to describe the particular manufacturing process.

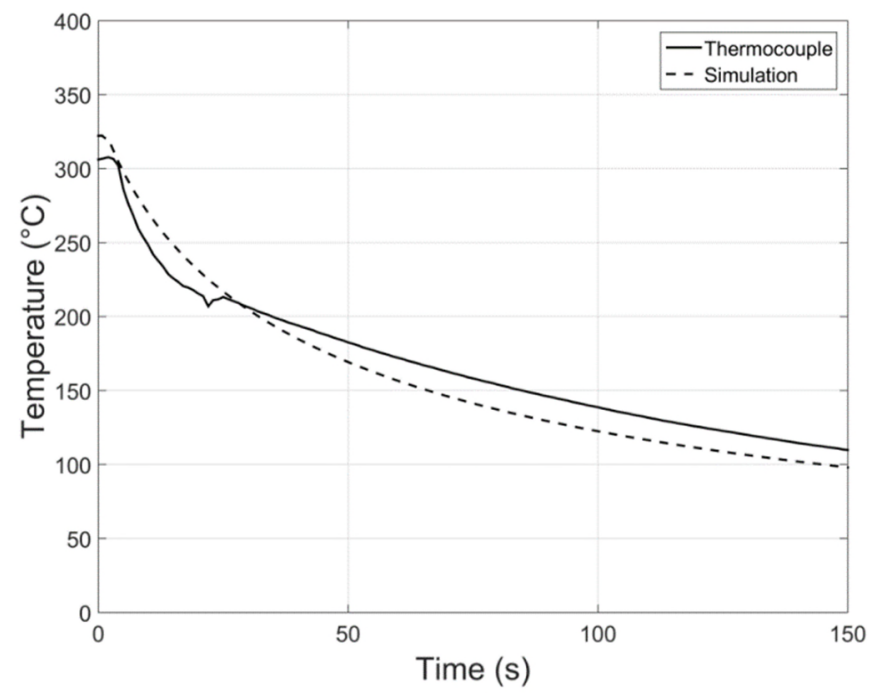

Figure 6: Lead interface temperature vs time (numerical vs. experimental results)

\section{Results}

\subsection{Introduction}

The most significant challenge of the lead sheet sand casting process is controlling the thickness of the lead sheet. We performed sand casting experiments to manufacture 3 different codes (standardisation of thickness) of lead sheet. The pouring temperature values were selected based on the interviews with the craftsmen and foundry engineers of Midland Lead. The obtained thickness readings at 5 equally spaced (by $20 \mathrm{~cm}$ ) along the longitudinal (x-) axis points located at the centre of the bed are listed in Table 3. It can be observed that although the mean thickness values are close to the desired ones, there are fluctuations around the mean value.

\begin{tabular}{|l|c|c|c|}
\hline Code & $\mathbf{6}$ & $\mathbf{7}$ & $\mathbf{8}$ \\
\hline Thickness (mm) & $\mathbf{2 . 6 5}$ & $\mathbf{3 . 1 5}$ & $\mathbf{3 . 5 5}$ \\
\hline Pouring temperature $\left({ }^{\circ} \mathbf{C}\right)$ & 355 & 347 & 342 \\
\hline Reading 1 & 2.37 & 2.94 & 3.44 \\
\hline Reading 2 & 2.45 & 2.91 & 3.58 \\
\hline Reading 3 & 2.28 & 3.21 & 3.68 \\
\hline Reading 4 & 2.77 & 3.11 & 3.37 \\
\hline Reading 5 & 2.81 & 3.18 & 3.49 \\
\hline Average & 2.54 & 3.07 & 3.51 \\
\hline Variance $\left(\mathbf{m m}^{\mathbf{2}}\right)$ & 0.046 & 0.015 & 0.012 \\
\hline
\end{tabular}

Table 3: Experimental thickness readings for various thickness codes 
It is therefore crucial to identify the effects of each process parameter on the final quality of the lead sheet in order to minimise thickness fluctuations on the final product. This section aims to demonstrate how common casting parameters affect quality, which is quantified on the basis of average sheet thickness and its standard deviation, by means of numerical modelling. The effect of clearance between the strickle and sand bed, melt temperature and speed of motion of strickle is presented in this section.

(a)

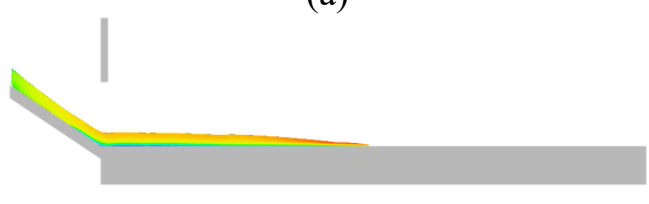

(c)

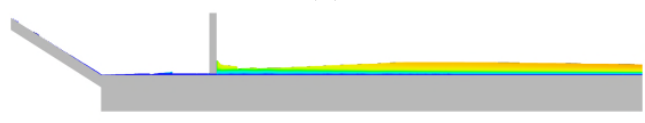

(b)

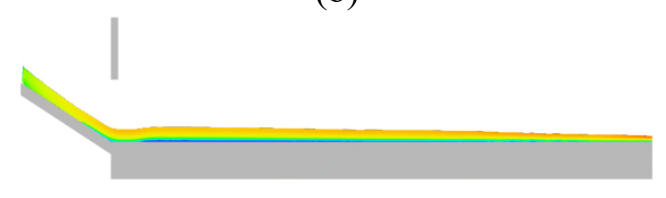

(d)

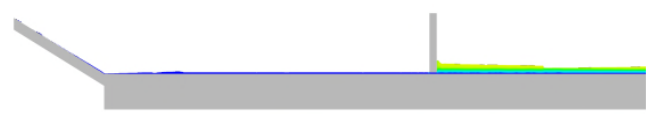

x-velocity (m/s)

Figure 7: Velocity profiles at (a) $t=1.2 \mathrm{~s}$, (b) $t=2.4 \mathrm{~s}$, (c) $t=3.6 \mathrm{~s}$, (d) $t=4.8 \mathrm{~s}$ and (e) $t=6 \mathrm{~s}$

The velocity profiles of the liquid lead are demonstrated in Figure 7 for evenly spaced time intervals. It can be observed that the maximum velocity is located at the metal front which reaches the end of the bed within the first $2.4 \mathrm{~s}$. The $\mathrm{x}$-velocity is zero at the liquid-solid interface due to the no-slip boundary condition imposed, while it gradually increases towards its maximum value located at the free surface. The strickle starts moving along the $\mathrm{x}$-axis at $\mathrm{t}=3 \mathrm{~s}$ and smears the melt. When the strickle exits the simulation domain, the fluid is stationary and has a uniform thickness along the sandbed with the exception of the first 0.75 meters of the sandbed. This is because of the additional non-solidified metal flowing over the inclined plane after the strickle starts moving. This observation is in agreement with experimental results and will be further discussed in the following sections.

\subsection{Clearance}

As mentioned in the introduction section, craftsmen control the lead sheet thickness by adjusting the clearance between the sandbed and the strickle. The thickness profiles for 4 different values of the clearance $c$ are illustrated in Figure 8. It has to be mentioned that the lower limit of the axis corresponds to the end of the inclined plane $(\mathrm{x}=0.5 \mathrm{~m})$, while the strickle velocity was set to $1 \mathrm{~m} / \mathrm{s}$. 


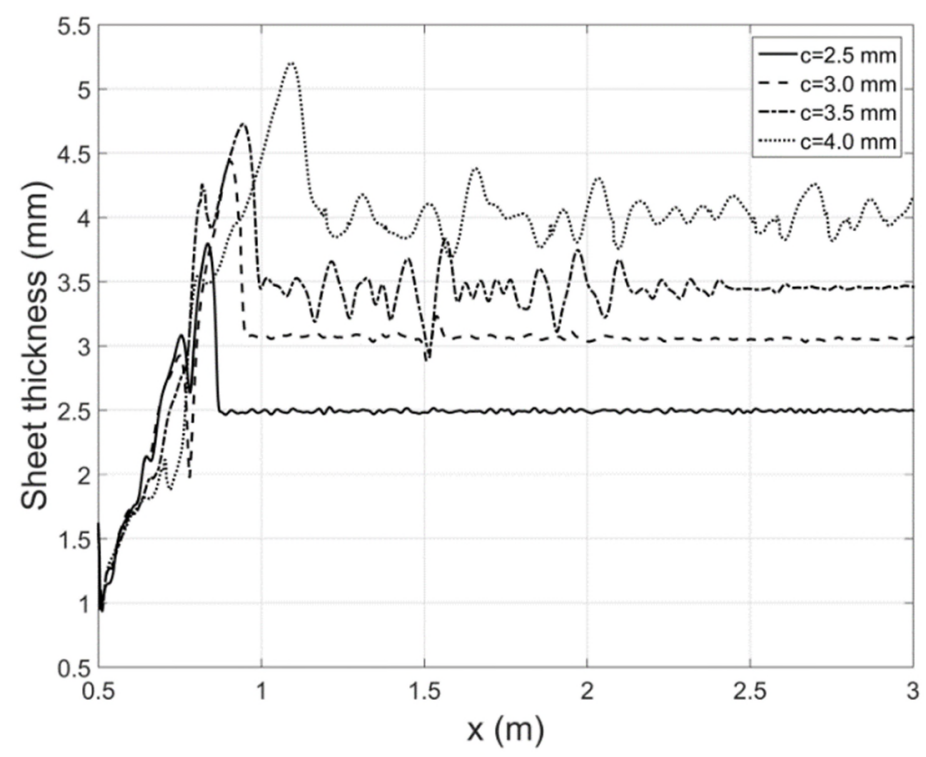

Figure 8: Thickness profiles for various values of clearance

It is evident that the sheet thickness gradually increases along the sandbed until it obtains a constant value for all cases examined. This region is characterised by the presence of hills and valleys and this behaviour is attributed to the fact that it lies in the proximity of the metal source which hinders immediate solidification due to the continuous flow of metal over the inclined plane. As we move away from this region the temperature of the liquid lead drops and a solid substrate is formed as illustrated in Figure 9.

Solid Fraction

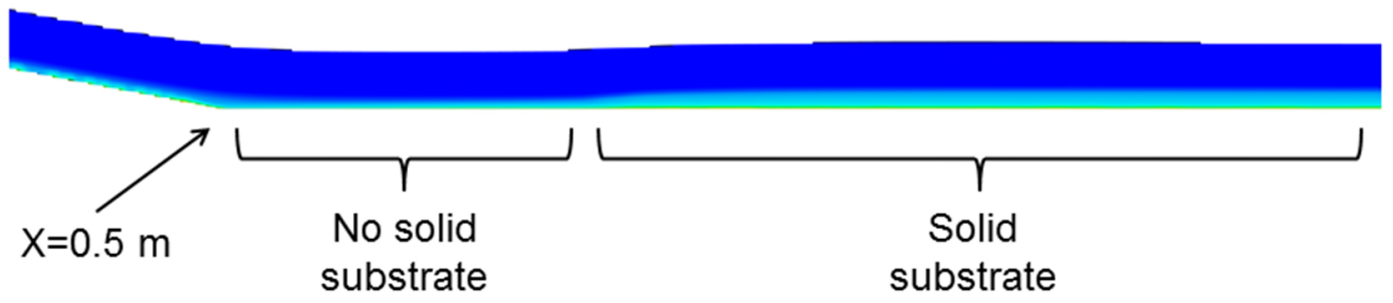

Figure 9: Solidification profile

As depicted in Figure 8, it is clear that more uniform sheet thickness can be achieved for lower values of the sheet thickness. This is because at the sandbed/lead interface the temperature is lower compared to the free surface. Consequently, the fluid viscosity decreases as we move away from the sandbed/lead interface and the sheet thickness becomes increasingly irregular. This in agreement with [35] in which an increase of the wrinkle (small amplitude surface wave) height is documented for lower values of the fluid viscosity. In Figure 10 the variance of the sheet thickness is plotted as a function of clearance. The variance for each case has been calculated over the cells that belong to the region where the thickness profile has been stabilised $(1.25 \mathrm{~m}<\mathrm{x}<3 \mathrm{~m})$. As expected, variance increases with clearance as the distance of the free surface from the interface increases due to the more irregular wrinkles induced. This observation suggests that for higher sheet thickness the strickle should start moving at a later stage in 
time so as to ensure that the solid substrate has been further extended along the y-direction and thus the viscosity has reached a higher value.

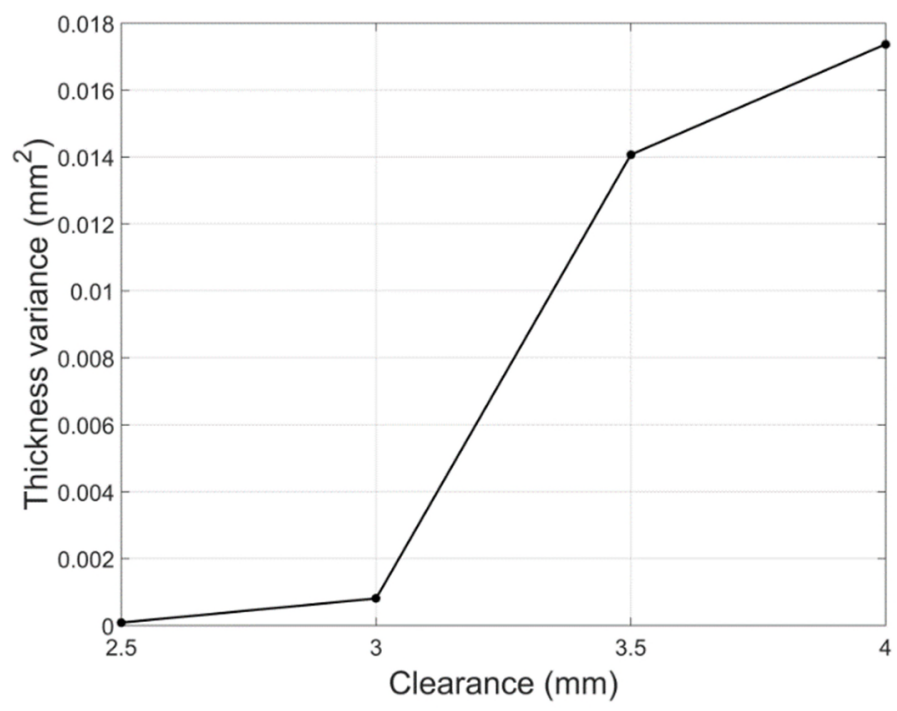

Figure 10: Thickness variance vs clearance

Despite the fact that higher clearance may lead to higher sheet thickness variance, the average sheet thickness, which has been calculated similarly to the variance, can be effectively controlled by the clearance as illustrated in Figure 11.

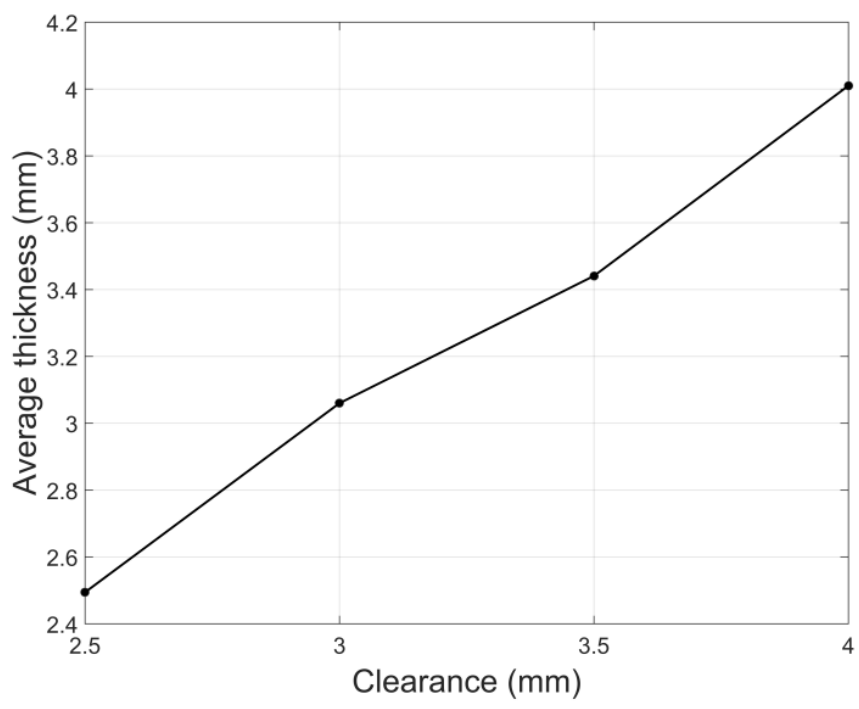

Figure 11: Average thickness vs clearance

\subsection{Strickle velocity}

In this section, the effects of the strickle velocity on the quality of the lead sheet will be discussed. 4 values of the strickle velocity have been examined: (a) $\mathrm{v}_{\mathrm{s}}=1 \mathrm{~m} / \mathrm{s}$, (b) $\mathrm{v}_{\mathrm{s}}=1.2 \mathrm{~m} / \mathrm{s}$, (c) $\mathrm{v}_{\mathrm{s}}=1.4 \mathrm{~m} / \mathrm{s}$, and (d) $\mathrm{v}_{\mathrm{s}}=1.6 \mathrm{~m} / \mathrm{s}$, while the clearance was set to $3 \mathrm{~mm}$. The corresponding thickness profiles are illustrated in Figure 12. As it can be observed, the x-coordinate for which the sheet thickness obtains an approximately uniform thickness is larger for higher values of the strickle velocity. This is because the lead surface being in contact with the strickle acquires the same velocity with the strickle due to the noslip boundary condition imposed. As a result, for higher strickle velocities, additional time is required 
for the liquid lead to be decelerated under the effect of the shear forces; consequently, the sheet thickness becomes constant for a larger value of the x-coordinate. Moreover, it is apparent that the sheet thickness is more uniform for lower values of the strickle velocity as verified in Figure 13. This is because surface wrinkles with higher amplitude are generated for higher values of the shear velocity, similarly to the observations reported in [36]. If the aforementioned surface wrinkles have not come to equilibrium by the time solidification occurs, additional thickness fluctuations and consequently higher thickness variation appear in the final cast sheet.

(a)

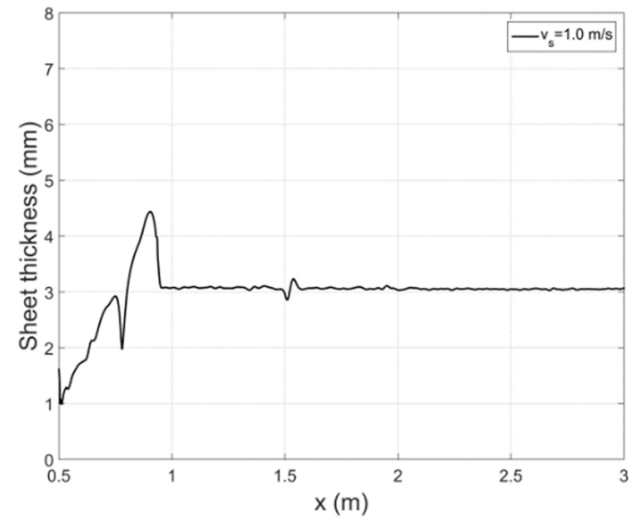

(c)

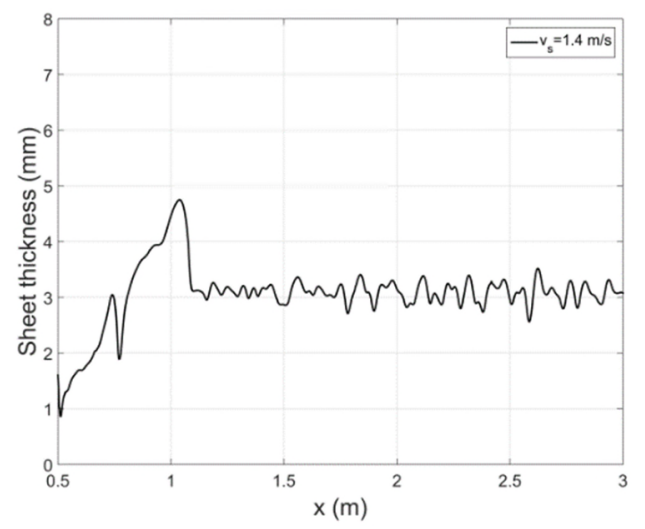

(b)

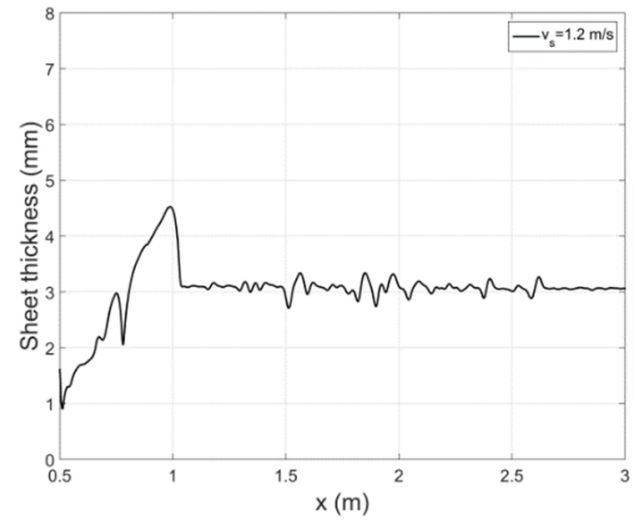

(d)

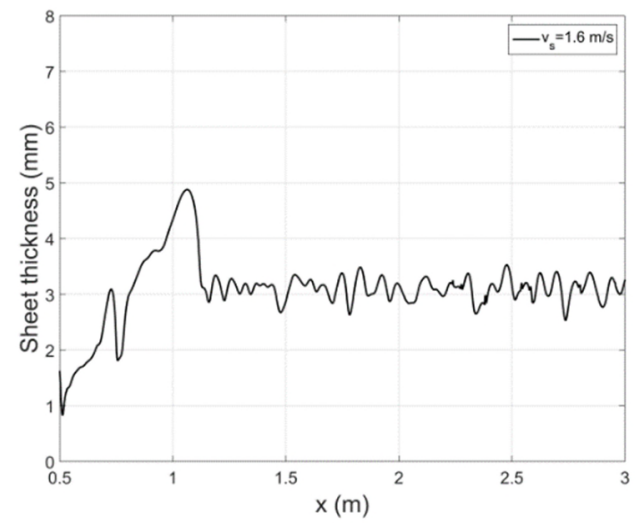

Figure 12: Thickness profiles for (a) $v_{s}=1 \mathrm{~m} / \mathrm{s}$, (b) $v_{s}=1.2 \mathrm{~m} / \mathrm{s}$, (c) $v_{s}=1.4 \mathrm{~m} / \mathrm{s}$, and (d) $v_{s}=1.6 \mathrm{~m} / \mathrm{s}$

By observing the thickness profiles of Figure 12 someone cannot distinguish any distinct effects of the strickle velocity on the average sheet thickness. In order to extract safer conclusions, the average sheet thickness $(1.25 \mathrm{~m}<\mathrm{x}<3.5 \mathrm{~m})$ was calculated and plotted against the strickle velocity as shown in Figure 14. It appears that the average sheet thickness is increasing linearly with the strickle velocity although it is not significantly affected by its value. This is because of the fact that the shear stress is higher for higher values of the strickle velocity and consequently a larger portion of the liquid metal follows the motion of the strickle. As a consequence, additional material is layered on top of the smeared surface. The displacement of the thickness peak towards the end of the bed as well as the increase of its amplitude for higher values of the strickle velocity, as illustrated in Figure 12, are attributed to the same reason.

By comparing Figure 10 and Figure 13 it can be concluded that the strickle velocity has a more significant effect on the thickness variance compared to clearance. It is therefore very significant that the craftsmen walk with a constant and relatively low speed alongside the bed. It is also highly likely that any strickle velocity fluctuations will also lead to variations in the sheet thickness. 


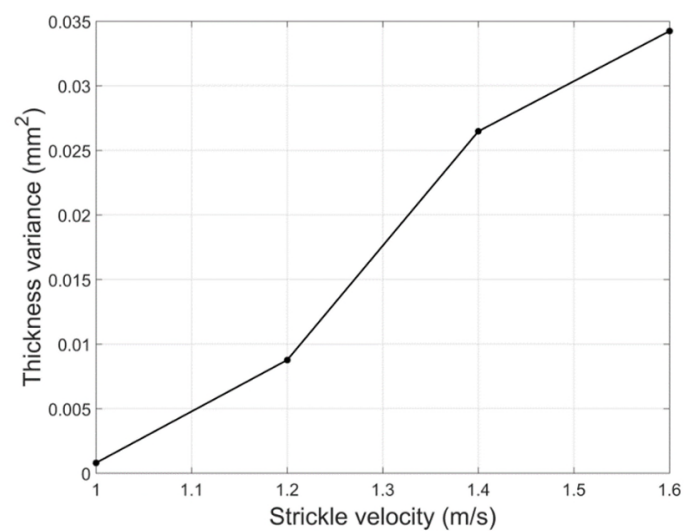

Figure 13: Thickness variance vs strickle velocity

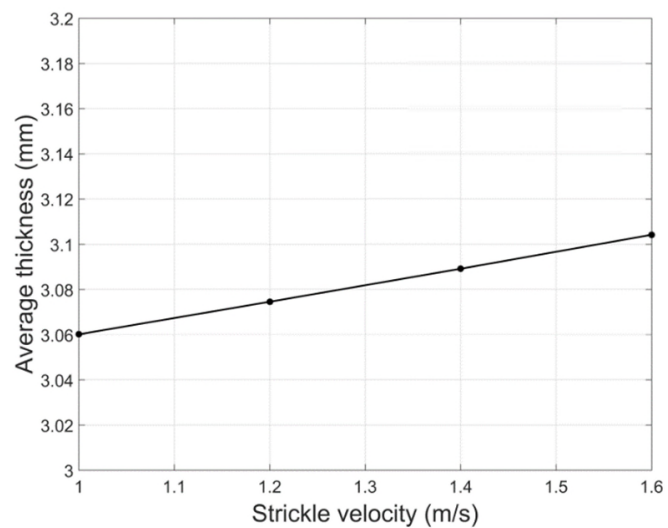

Figure 14: Average thickness vs strickle velocity

\subsection{Pouring temperature}

In this section, the effects of the lead charge pouring temperature $\left(T_{P}\right)$ on the quality of the lead sheet thickness will be discussed. In section 3.1, it has been pointed out that higher temperature of the melt should be associated with increased irregularity of the final lead surface due to the lower viscosity. For the same reason a similar trend is observed in Figure 15 which demonstrates the thickness profiles obtained for 4 different values of the pouring temperature: (a) $\mathrm{T}_{\mathrm{P}}=345{ }^{\circ} \mathrm{C}$, (b) $\mathrm{T}_{\mathrm{P}}=350{ }^{\circ} \mathrm{C}$, (c) $\mathrm{T}_{\mathrm{P}}=355^{\circ} \mathrm{C}$ and (d) $\mathrm{T}_{\mathrm{P}}=360^{\circ} \mathrm{C}$.

(a)

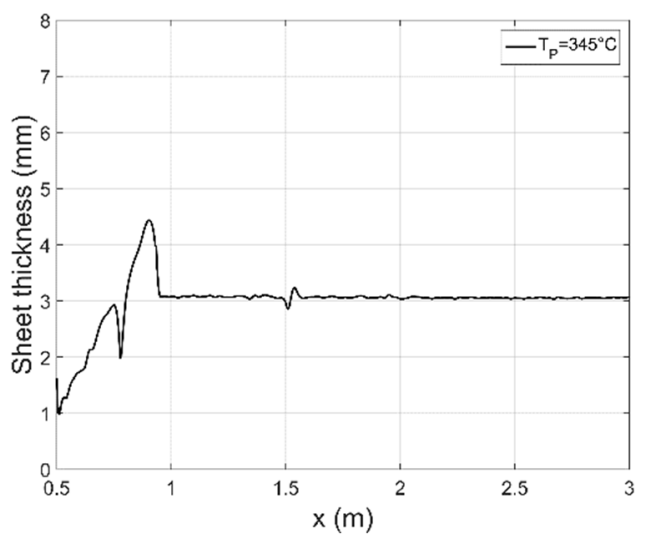

(c)

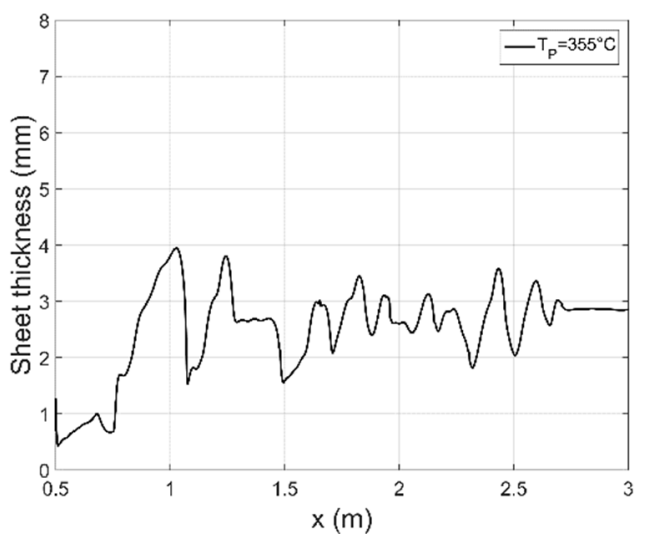

(b)

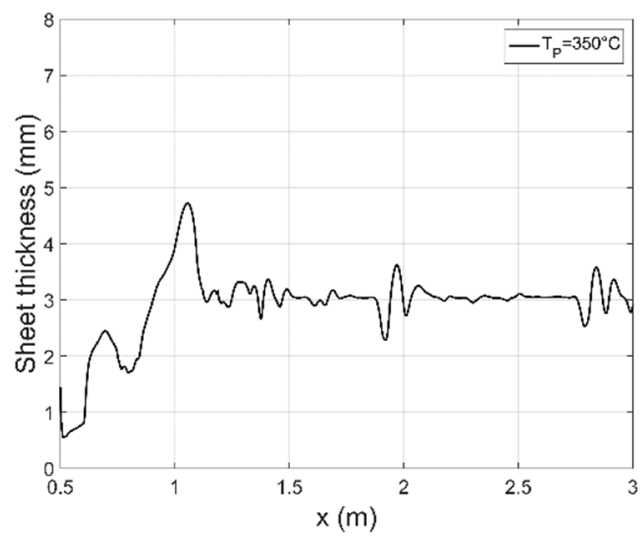

(d)

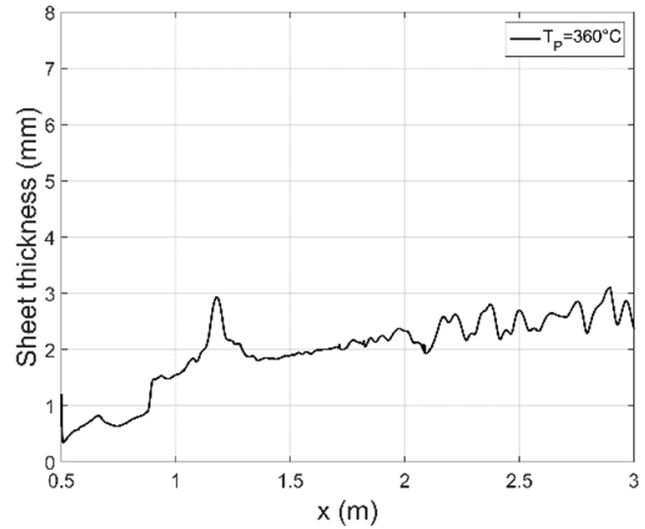

Figure 15: Thickness profiles for (a) $T_{P}=345^{\circ} \mathrm{C}$, (b) $T_{P}=350^{\circ} \mathrm{C}$, (c) $T_{P}=355^{\circ} \mathrm{C}$ and (d) $T_{P}=360^{\circ} \mathrm{C}$ 
It is evident that the average sheet thickness decreases with higher pouring temperature. However, in the case of $\mathrm{T}_{\mathrm{P}}=360^{\circ} \mathrm{C}$ the sheet thickness is much lower than the desired value $(3 \mathrm{~mm})$. This is because of the increased fluidity due to the lower viscosity of the molten lead. Due to the higher temperature and the consequent delayed solidification stage the liquid is decelerated at a later stage in time. This leads to lower average sheet thickness compared to lower pouring temperatures (Figure 16). This result is in agreement with the conducted experiments which report that the average sheet thickness reduces with the pouring temperature and that it is impossible to obtain the desired thickness profiles for pouring temperatures higher than $355^{\circ} \mathrm{C}$.

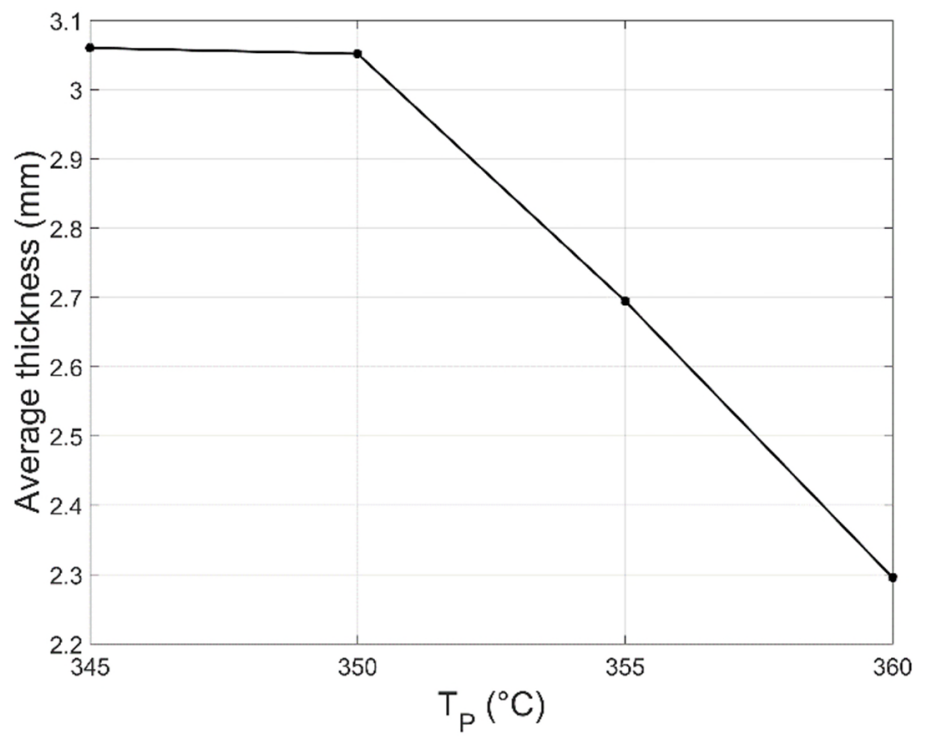

Figure 16: Average sheet thickness vs pouring temperature

By observing Figure 15(a), (b) and (c), it can be seen that increased pouring temperature leads to more irregular lead sheet thickness profiles. This is because increased fluidity induces additional surface wrinkles. However, in Figure 15(d) it appears that the surface irregularities are decreased compared to Figure 15(c). This is attributed to the delayed solidification stage which allows the fluid to equilibrate under the effects of surface tension and gravity and obtain a smoother thickness profile (Figure 17).

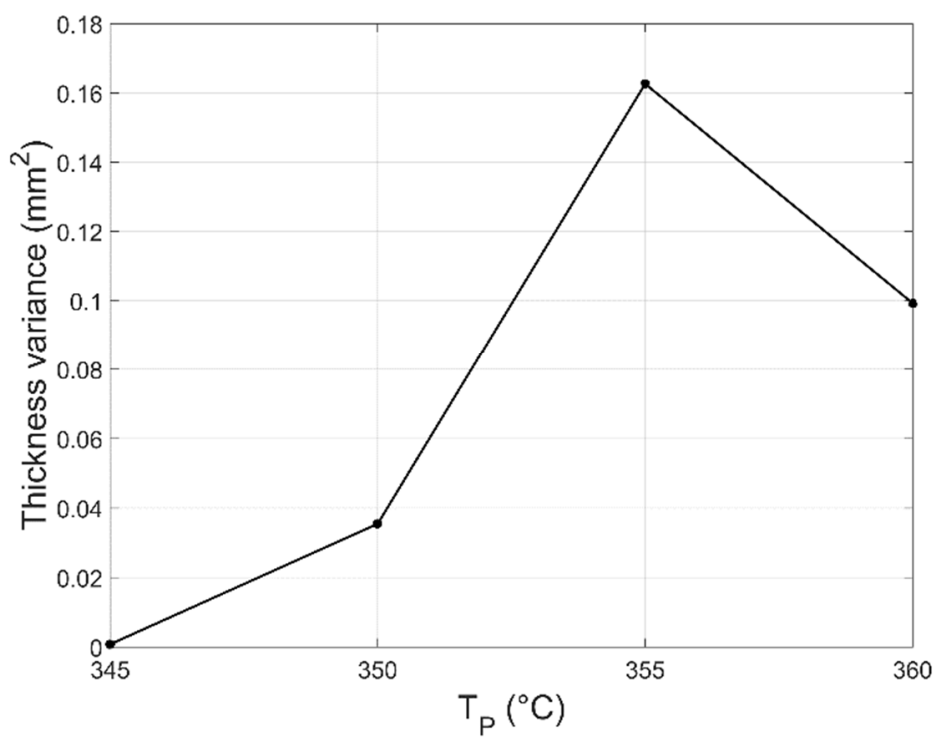

Figure 17: Thickness variance vs pouring temperature 
By comparing the variance profiles (Figure 10, Figure 13 and Figure 17) for the 3 process parameters under investigation (clearance, strickle velocity and temperature respectively) it can be concluded that temperature can potentially have the most detrimental effect on the quality of the final product. The value of the pouring temperature should be therefore carefully selected as very low temperature will lead to premature solidification but on the other hand very high temperature will lead to either additional surface irregularities or a mean thickness lower than the desired value.

\section{Conclusions}

This investigation is the first effort to bridge the traditional lead sheet sand casting process with numerical simulations. A 2-dimensional CFD model was developed to simulate the melt flow and solidification of lead during the sand casting process. The objective of this study is the investigation of the effects of process parameters such as the pouring temperature, strickle velocity and clearance between the sandbed on the strickle on the quality of the lead sheet.

Simulation results are in good agreement with experimental observations. More specifically, it is observed that the clearance between the sandbed and the strickle can be effectively used to control the sheet thickness for a specific range of pouring temperature values. The average sheet thickness increases with higher values of the strickle velocity and decreases with pouring temperature. However, an increase in any of the above-mentioned parameters leads to an increase in the thickness variance. Moreover, the variation is relatively low for thinner lead sheets. This behaviour is attributed to the lower viscosity of lead in the areas far from the sandbed/lead interface. This issue can potentially be solved by delaying the commencement of the strickle movement in order to allow a thicker solid substrate to be formed along the normal direction. Finally, it is observed that the initial $0.5-0.75 \mathrm{~m}$ of the cast sheet has in general lower thickness compared to the rest, high variation and consequently cannot be used for practical applications. This result is in agreement with experimental observations.

The present study can be used as a stepping stone for further numerical investigation of the sand casting method for producing lead sheets. The investigation of the effects of additional process characteristics such as the inclination of the sandbed and the strickle geometry on the quality of the cast sheet should be further investigated. Moreover, the current model can be used as the basis of an optimisation case study aiming at selecting the optimum process parameters for superior lead sheet quality.

\section{Acknowledgements}

The authors would like to appreciate the support provided by Midland Lead Operations, Derby and Innovate UK through the KTP program (Project Number 9855) 


\section{References}

1. Singha SK, Singh SJS (2015) Analysis and optimization of sand casting defects with the help of artificial neural network. Int J Res Eng Technol 04:24-29

2. Khandelwal H, Ravi B (2016) Effect of molding parameters on chemically bonded sand mold properties. J Manuf Process 22:127-133 . doi: 10.1016/j.jmapro.2016.03.007

3. Rocca E, Mirambet F, Steinmetz J (2004) Study of ancient lead materials: A gallo-roman sarcophagus - contribution of the electrolytic treatment to its restoration. J Mater Sci $3: 2767-2774$

4. Blaskett DR, Boxall D (1990) Lead and its Alloys. Ellis Horwood

5. Home | ILA - International Lead Association Website. https://www.ila-lead.org/

6. Davidson AJ, Binks \& SP, Gediga \& J (2016) Lead industry life cycle studies: environmental impact and life cycle assessment of lead battery and architectural sheet production. Int J Life Cycle Assess 21:1624-1636

7. Rowe D (2017) Lead manufacturing in Britain: a history

8. Prabhakar A, Mielnicka J, Jolly M, Salonitis K (2018) Improving Energy Efficiency in Direct Method for Continuous Casting of Lead Sheets. In: TMS Annual Meeting \& Exhibition. Springer, Cham, pp 121-132

9. Associated Lead Mills Ltd \& Jamestown Metals Ltd Craftsman's Guide to Rolled Lead Sheet

10. Prabhakar A, Salonitis K, Jolly M (2019) Characterisation of Lead Sheet Manufactured Using Traditional Sand-Casting Technique. In: Shape Casting. Springer, pp 283-292

11. Whillock S, Charles JA, Smith GC (1989) Microstructures and mechanical properties of milled and continuously cast lead sheet Part 1 Microstructures. Mater Sci Technol 5:1074-1083 . doi: 10.1179/mst.1989.5.11.1074

12. Whillock S, Charles JA, Smith GC (1991) Microstructures and mechanical properties of milled and continuously cast lead sheet. Mater Sci Technol 7:1116-1127 . doi: 10.1179/mst.1991.7.12.1116

13. Chopra O, Niessen P (1975) Solidification of Lead and Lead Alloys in Continuous Drum Sheet Casting. Zeitschrift fuer Met Res Adv Tech 66:10-16

14. Zhang SX, Myo HM, Lim KB, et al (2007) Processing of thin metal strip by castingcum-rolling. J Mater Process Technol 192-193:101-107 . doi: 10.1016/J.JMATPROTEC.2007.04.075

15. Kumar AM., MEhrotra S. (1991) Effect of Process Parameters on the Performance of a Single Roll Continuous Strip Caster. In: 1st European Conference on Continuous Casting. pp 23-25

16. Shamsi MRRI, Mehrotra SP (1993) A two-dimensional heat and fluid-flow model of single-roll continuous-sheet casting process. Metall Mater Trans B 24:521-535 . doi: 10.1007/BF02666435

17. Reikher A, Pillai KM (2013) A fast simulation of transient metal flow and solidification 
in a narrow channel. Part II. Model validation and parametric study. Int J Heat Mass Transf 60:806-815 . doi: 10.1016/j.ijheatmasstransfer.2012.12.061

18. Reilly C, Green NR, Jolly MR (2013) The present state of modeling entrainment defects in the shape casting process. Appl Math Model 37:611-628

19. Reis A, Xu Z, Tol RV, Neto R (2012) Modelling feeding flow related shrinkage defects in aluminum castings. J Manuf Process 14:1-7 . doi: 10.1016/j.jmapro.2011.05.003

20. Sulaiman S, Hamouda AMS (2004) Modelling and experimental investigation of solidification process in sand casting. J Mater Process Technol 155:1723-1726 . doi: 10.1016/j.jmatprotec.2004.04.153

21. Kermanpur A, Mahmoudi S, Hajipour A (2008) Numerical simulation of metal flow and solidification in the multi-cavity casting moulds of automotive components. J Mater Process Technol 206:62-68 . doi: 10.1016/J.JMATPROTEC.2007.12.004

22. Papanikolaou M, Pagone E, Georgarakis K, et al (2018) Design optimisation of the feeding system of a novel counter-gravity casting process. Metals (Basel) 8: . doi: $10.3390 /$ met 8100817

23. Papanikolaou M, Pagone E, Salonitis K, et al (2018) A Computational Framework Towards Energy Efficient Casting Processes. In: International Conference on Sustainable Design and Manufacturing. pp 263-276

24. Krimpenis A, Benardos PG, Vosniakos G-C, Koukouvitaki A (2006) Simulation-based selection of optimum pressure die-casting process parameters using neural nets and genetic algorithms. Int J Adv Manuf Technol 27:509-517 . doi: 10.1007/s00170-0042218-0

25. (2019) FLOW-3D® Version 12.0 [Computer software]. Santa Fe, NM: Flow Science, Inc.

26. Barkhudarov M, Hirt C (1995) Casting simulation: Mold filling and solidification-Benchmark calculations using FLOW-3D ${ }^{\circledR}$

27. Hirt CW, Nichols BD (1981) Volume of fluid (VOF) method for the dynamics of free boundaries. J Comput Phys 39:201-225

28. Online Materials Information Resource - MatWeb. http://www.matweb.com/

29. Ho K, Pehlke RD (1985) Metal-Mold interfacial heat transfer. Metall Trans B 16:585594 . doi: 10.1007/BF02654857

30. Lead, $\mathrm{Pb}$. http://www.matweb.com/search/DataSheet.aspx?MatGUID=ebd6d2cdfdca4fc285885c c4749c36b1\&ckck=1. Accessed 6 Dec 2018

31. Barkhudarov MR (1995) Enhancement to heat transfer and solidification shrinkage models in Flow-3D. Flow Sci Inc, Rep FSI-95-TN43

32. Tota P (2009) Turbulent Flow Over a Backward-Facing Step Using the RNG k- $\varepsilon$ Model

33. Stathopoulos N, El Mankibi M, Santamouris M (2017) Numerical calibration and experimental validation of a PCM-Air heat exchanger model. Appl Therm Eng 114:1064-1072 
34. Banaszek J, McFadden S, Browne DJ, et al (2007) Natural convection and columnar-toequiaxed transition prediction in a front-tracking model of alloy solidification. Metall Mater Trans A 38:1476-1484

35. Paquier A, Moisy F, Rabaud M (2016) Viscosity effects in wind wave generation. Phys Rev Fluids 1:083901 . doi: 10.1103/PhysRevFluids.1.083901

36. van Gastel K, Janssen PAEM, Komen GJ (1985) On phase velocity and growth rate of wind-induced gravity-capillary waves. J Fluid Mech 161:199-216 
2019-11-20

Sand casting of sheet lead: numerical simulation of metal flow and solidification

\author{
Prabhakar, Arun
}

Springer

Prabhakar A, Papanikolaou M, Salonitis K, Jolly M. (2020) Sand casting of sheet lead: numerical simulation of metal flow and solidification. International Journal of Advanced Manufacturing Technology, Volume 106, January 2020, pp. 177-189

https://doi.org/10.1007/s00170-019-04522-3

Downloaded from Cranfield Library Services E-Repository 